JISTE, Vol. 25, No. 1, 2021

\title{
Preferred Learning Style of Students of Nangkor Central School, Bhutan
}

\author{
Prem Prasad Timisina, Ugyen Tschewang, Nima Tshering, Rinchen, Sherab, Karma Dawa, \\ Tschering Dorji and Phurba Tashi \\ Nangkor High School, Bhutan
}

\begin{abstract}
Students preferentially absorb and process information in diverse ways. Pedagogy should vary accordingly. The knowledge of teachers on the learners' preferred learning styles plays a pivotal role in better teaching and learning processes, contributing to a better-quality education. Still, little is known about the preferred learning style of learners. In the present study, the VARK (visual, aural, read or write, kinaesthetic) model version 8.01 survey questionnaire was adapted and given to 215 middle and higher secondary students. Using descriptive analysis of correlation, frequency and percentage, the study revealed that the preferred learning styles of students are aural (A) and kinaesthetic $(\mathrm{K})$ with the smallest preference given to visual $(\mathrm{V})$. The findings showed that male and female participants' preferences were the same, and that high-achiever learners prefer K. Recommendations from the findings apply to both the classroom and teacher training opportunities.
\end{abstract}

Keywords: gender learning preferences, learning style, Nangkor, Bhutan, teacher education.

\section{Context}

Nangkor Central School (NCS) is nestled at the foot of Shumar Gewog in Pemagatshel District, Bhutan. Since its inception in 1997, the school has hosted a diversity of students with the majority coming from economically disadvantaged family backgrounds. Set with boarding facilities and a conducive learning environment, the school houses classes nine to twelve (ages 15 to 17). At present, there are 29 teachers, including the principal, 28 supporting staff and 515 students.

Improving education in Bhutan is a national concern, and the Bhutanese education system has seen unprecedented reforms in recent decades since its inception. Many challenges have been met, but there are more that need to be addressed. It was found in several studies conducted by the Royal Education Council that a gap exists between the teachers' approaches to pedagogy and the students' learning (Ministry of Education, 2014). As an intervention, a series of professional development programmes were provided to teachers by Teacher Professional Support Division under Ministry of Education. As envisioned in the Education Blueprint, the nature of learning has transitioned from a culture of fear to one of participation. However, in the aftermath of the COVID-19 pandemic, the usual mode of contact teaching culminated into an e-learning strategy for meaningful student engagement, at least until it is superseded by a 'new normal' approach, yet to be determined. 
Education stakeholders, especially the educators in the schools, are constantly looking for avenues to improve students' academic performance. Understanding the preferred learning style of students is seen as one path to improve the academic learning. One study (Dalaman, et al., 2019) suggested that knowing the preferred learning style of students enables academic success by providing more effective solutions to problems encountered in the teaching-learning process. This is accomplished while educators are constantly striving to diagnose the factors that influence the academic performance through various research undertakings, consultations and conferences. However, there has been no empirical evidence of preferred learning styles of Bhutanese students, and the present study, which is bedded on the VARK model, is the first of its kind in our school. VARK refers to the four types of learning styles: visual, aural, reading or writing, and kinaesthetic, and maintains that students have different styles related to how they process information, often referred to as preferred learning style (Fleming, 1995).

In the past four consecutive years, students' academic performance has been progressively above expectations; however, there were no definite pedagogical factors that could help explain the results. With the outbreak of COVID-19 pandemic, the modes of teaching-learning have changed dramatically, with the rise of e-learning on digital platforms. The research study by Li and Lalani (2020) on the effectiveness of online teaching suggested that, for those students who have access to the right technology, there was evidence that learning online was effective by increasing retention of information. There were, however, challenges to overcome. Some students without reliable internet access or technology struggled to participate in digital learning. Consequently, stakeholders determined it to be imperative to discover the learning preferences of the students in order to cater meaningfully to their needs, based on a study conducted by Butler (2004). In this study about students' learning styles and their preferences for online instructional methods, it was revealed that there were several significant positive and negative relationships between learning styles and instructional methods.

\section{Literature review}

Educational research has identified several factors that account for potential differences in how students learn. One of these factors often cited in the research is a student's preferred learning style (McKenna, et al., 2018; Romanelli, et al., 2009; Willingham, et al., 2015). The relationship between learning styles and learning achievement outcomes remains argumentative (McKenna et al., 2018); however, it has been generally accepted that individuals' learning styles have an impact on their performance and achievement of learning outcomes (Dalaman et al., 2019).

\section{Learning Style Theories}

The standard definition for learning style is "cognitive, affective, and physiological traits that are relatively stable indicators of how learners perceive, interact with, and respond to the learning 
environment" (Romanelli et al., 2009, p.1). According to Willingham et al. (2015), scientists such as Carl Jung, Felder and Silverman, Gregorc, and Kolb, have devised numerous models of learning styles, many of which are used in various research studies. Learning styles theories are varied, yet common among them is the idea that individuals learn in different ways and that learning can be optimized by tailoring instruction to their style (Willingham et al., 2015).

\section{The VARK model}

One of the most recent and versatile models that looks at learning styles is the VARK model designed by Neil Fleming (McKenna et al., 2018). The VARK model uses a questionnaire that assesses an individual's learning styles. It was primarily developed at Lincoln University of New Zealand in 1998 and has undergone various modifications. According to McKenna et al. (2018) many studies were conducted using this pretested and validated survey questionnaire in research in different fields and disciplines. The VARK questionnaire is based on three principles:

1. everyone has their own styles to acquire knowledge,

2. learner's motivation is increased when different learning styles of learners are considered by the teacher and

3. educational concepts are learned through deployment of four sensory modalities and perceptions.

This instrument, which is based on interaction and response to the learning environment of the students, divides students into four categories: visual, aural, reading or writing and kinaesthetic (Karim, 2014).

Visual learners tend to prefer information presented through graphs, diagrams, essays and charts, which allow them to assimilate information best as they can visualize relationships and ideas. When instructors illustrate or diagram their lectures on a whiteboard, visual learners may remember the information better (Flavin, 2019; Fleming, 1995).

Aural learners prefer listening to information rather than reading it or seeing it visually displayed. They may speak and read slowly and tend to be linear thinkers, who may repeat concepts that they hear out loud. When it comes to studying, an auditory learner might remember material best if they talk about it with someone else, since it will be easier for them to recall a conversation (Flavin, 2019; Fleming, 1995).

Reading and writing learners tend to be comfortable with the written word. They prefer to consume information by reading texts and can further absorb information by condensing and rephrasing it. The traditional school textbook and annotation process works well for the reading or writing learning style (Flavin, 2019; Fleming, 1995).

Kinaesthetic learners prefer to learn through simulation and real-life experiences, often described as hands-on activities. They learn best by doing and may feel uneasy if forced to sit for long periods of time. Sometimes, even being physically engaged will help them retain information better (Flavin, 2019; 
Fleming, 1995).

\section{Methodology}

\section{Significance of the study}

The very endeavour of this survey study was to advance our concerted strategies into school policy for constant rise in academic excellence and to fulfil the school's mission: "To grow into an Institute of Ideal Bhutanese citizen' and become the Peak of Learning Centre of the East" (NCS, 2018, p. 4). It was also designed to provide teachers with approaches of culturally responsive teaching that will meet the needs of diverse individuals' preferences of learning. This study would further recommend on the feasibility of e-learning pedagogies and incorporation of it into the mainstream of teaching-learning process post COVID-19 situation.

\section{Research Design}

This study attempted to investigate the preferred learning styles of the secondary students of NCS in eastern district of Bhutan. It was designed within the theoretical paradigm of post-positivism where cross-sectional survey was used to obtain students' preferred learning style (Creswell, 2003). In such an approach, surveys are commonly used to obtain reliable data that describe either past or existing situations of the learning environment and academic performances of the students. The cross-sectional survey design was employed as it enables the researchers to understand the prevalence of attributes for a sample of population at one point of time (Creswell, 2003). Subsequently, quantitative research method was used.

\section{Participants}

The questionnaire was administered to a representative population. Students of different grades were involved in the sample. Stratified random sampling technique was used to select the representative populations of the study. According to Creswell (2003), random sampling is a sampling technique where each sample has an equal probability of being chosen mainly for unbiased representation of the total population. The goal of stratified random sampling is to select a sample in such a way that the target subgroups are represented in the sample in the same proportion that they exist in the population. The sample of this study consisted of 215 students, which was derived from an online sampling calculator. Selection of participants from each class was randomly done. All participants signed an informed consent document, ensuring strict confidentiality that the information would be used for research purposes only.

\section{Research Instrument}

The research instrument used in this study was adapted from the VARK model close-ended survey questionnaire. The questionnaire was used as it enables the researchers to reach a large sample within a 
short span of time (Creswell, 2003). Survey questionnaire contained two parts. The first section provided demographic information of the students. The second part contained 16 items investigating the learning styles of students. A few questionnaires items were adapted mainly to contextualize for quick comprehension of it by our participants. Permission to use the questionnaire was granted by its author.

\section{Data Analysis}

The data were processed and analysed quantitatively using Microsoft Excel (2007). After checking for completeness, data were coded and entered into a computer system. As stated above, the questionnaire consisted of 16 items and students were given the option to tick only one option for each item, depending upon their preferences. The analysis used by Das, Chakraborty and Sukul (2020) was used to obtain the preferred learning style, which was focused on finding the preferred unimodal learning style by restricting multiple responses to a single question. The notion behind this approach was to discover the preferred mode of learning in the study population. In addition, the descriptive analysis was carried out to profile sample characteristics and to determine major patterns that emerged from the data. Major findings from the data sets were presented in the form of percentage and frequency distributions in the form of tables and charts. Further, correlational analysis was used to determine prevalence and relationship among the variables used in the study.

\section{Research Questions}

In order to discover more about the above ideas, the study endeavoured to address the following research questions:

1. What are the learning style preference of NCS's students of 2020?

2. Does NCS students' learning style vary depending on their gender, grade and score?

\section{Findings}

This section presents the findings of the study in relation to the objectives of the study. It includes demographic findings, overall preferred learning style, preferred learning style based on gender and previous academic score, and preferred learning style based on grade level.

Table 1 shows basic demographic information of the participants. Concerning the school class level, $10.7 \%$ of the students were in class nine, $20.5 \%$ in class ten, $26.0 \%$ in class eleven and, finally, $42.8 \%$ were in class twelve. Further, $52.1 \%$ of the respondents were male with $47.9 \%$ being female. Lastly, $76.7 \%$ of the participants were boarders at their schools and $23.3 \%$ were day students. 


\section{Table 1}

Demographic Information of the Sampled Respondents

\begin{tabular}{lcc}
\hline & Frequency & Percentage \\
\hline Class & 23 & \\
Nine & 44 & $10.7 \%$ \\
Ten & 56 & $20.5 \%$ \\
Eleven & 92 & $26.0 \%$ \\
Twelve & & $42.8 \%$ \\
\hline Gender & 112 & $52.1 \%$ \\
Male & 103 & $47.9 \%$ \\
Female & 160 & $76.7 \%$ \\
\hline Students & 55 & $23.3 \%$ \\
Boarders & & \\
Day-students & & \\
\hline
\end{tabular}

Figure 2 represents the cumulation of all the academic scores completed during a school year of the sampled respondents. One percent of the participants scored below $35 \%, 2 \%$ scored between $35 \%$ and $50 \%$, while $40 \%$ of the sample scored an average between $51-65 \%$. Further, $37 \%$ scored an average of $66-$ $75 \%$ and a further $20 \%$ scored above $76 \%$.

Finally, for demographic information, Figure 3 shows the socio-economic background of diverse sampled respondents. It was evident that the majority of the participants (69\%) have parents who are farmers, $18 \%$ have parents who are civil servants, $12 \%$ claimed that their family were in some type of business and $1 \%$ from gave other socio-economic backgrounds for their parents' occupation.

\section{Figure 2}

Academic Learning Score of the Sampled Respondents

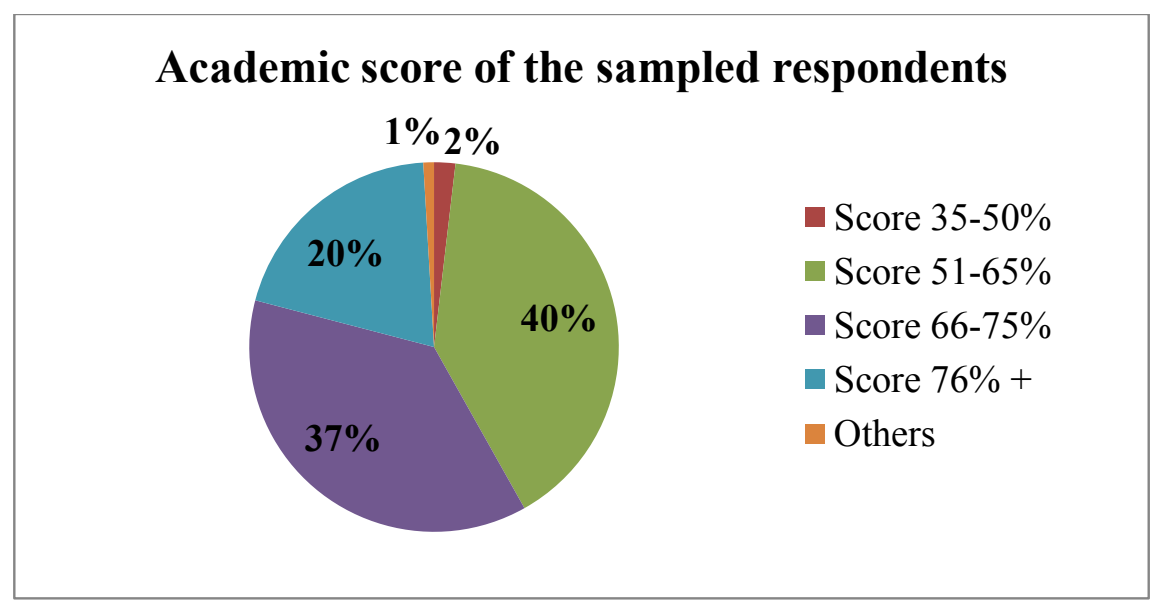




\section{Figure 3}

Socio-economic Background of the Sampled Respondent

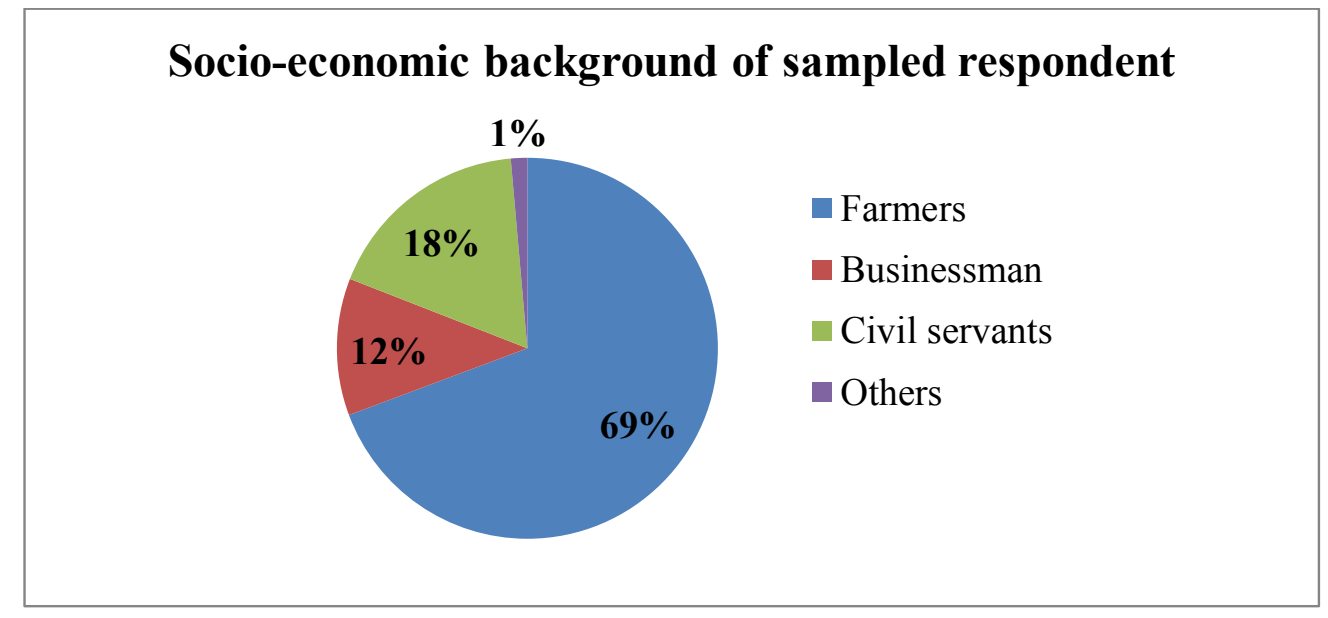

Table 2 shows the preferred learning style of the students. Of the total respondents, $16.52 \%$ indicated that they prefer a visual approach to learning. Another $31.17 \%$ of the students preferred to learn by listening and speaking. In addition, $21.25 \%$ preferred to learn through writing and reading. The remainder or $31.06 \%$, of the sampled respondents preferred to learn by kinaesthetic means. The statistics revealed that the majority of NCS students favoured aural learning styles $(31.17 \%)$, while the fewest preferred visual $(16.52 \%)$. There is narrow difference between aural and kinaesthetic way of learning.

\section{Table 2}

Preferred Learning Style of Student

\begin{tabular}{cc}
\hline Learning Style & Percentage \\
\hline Visual & $16.52 \%$ \\
Aural & $31.17 \%$ \\
Read/Write & $21.25 \%$ \\
Kinaesthetic & $31.06 \%$ \\
\hline
\end{tabular}

Table 3 describes the preferred learning style of the students in terms of their gender. Males most preferred learning style is kinaesthetic approaches (31.50\%) and least is visual (16.56\%) while females tended most towards aural (31.78\%) the most and visual (16.46\%) the least. Both male and female prefer least for visual way of learning. However, for most preferred learning style, there is a narrow difference between aural and kinaesthetic way of learning for females. Further, the data for the preferred learning style based on gender across each style suggest that the preferences between the genders is similar. 
JISTE, Vol. 25, No. 1, 2021

\section{Table 3}

Preferred Learning Style Based on Gender

\begin{tabular}{ccc}
\hline Learning Style & Male & Female \\
\hline V & $16.56 \%$ & $16.46 \%$ \\
A & $30.58 \%$ & $31.78 \%$ \\
R & $21.35 \%$ & $21.15 \%$ \\
K & $31.50 \%$ & $30.60 \%$ \\
\hline
\end{tabular}

Table 4 shows the correlation between preferred learning style of male students and female students. For those respondents, the preferred learning style scores of males were positively correlated with that of females, $r=0.99$.

\section{Table 4}

Correlation between Preferred Learning Style of Male and Female Students

\begin{tabular}{lcc}
\hline & Male & Female \\
\hline Male & 1 & 0.99 \\
Female & 0.99 & 1 \\
\hline
\end{tabular}

The next analysis was based on participants' grading category done in Bhutan. The classes 9 and 10 were graded as middle secondary (MS) students and the classes 11 and 12 were labelled in higher secondary (HS) students. Table 5 shows the learning style preference statistics of MS and HS students. The most commonly chosen preferred learning styles of MS and HS students were aural (30.42\%) and kinaesthetic (37.67\%), respectively. While the least preferred learning style for both MS and HS students was visual (17.30\% and $19.25 \%)$.

\section{Table 5}

Preferred Learning Style Based on Grade Level

\begin{tabular}{ccc}
\hline Learning Style & $\begin{array}{r}\text { Middle Secondary students } \\
\text { (Classes 9 \& 10) }\end{array}$ & $\begin{array}{c}\text { Higher Secondary students } \\
\text { (Classes 11 \& 12) }\end{array}$ \\
\hline V & $17.30 \%$ & $19.25 \%$ \\
A & $30.42 \%$ & $37.59 \%$ \\
R & $22.33 \%$ & $24.73 \%$ \\
K & $29.95 \%$ & $37.67 \%$ \\
\hline
\end{tabular}

Table 6 shows the correlation between preferred learning style of MS students and HS students. It is evident that for those respondents in this survey, the preferred learning style scores of MS students were positively correlated with that of HS students, $r=0.995$. 


\section{Table 6}

Correlation between Preferred Learning Styles of MS and HS Students

\begin{tabular}{lcc}
\hline & $\begin{array}{c}\text { Middle Secondary students } \\
\text { (Classes 9 \& 10) }\end{array}$ & $\begin{array}{c}\text { Higher Secondary students } \\
\text { (Classes 11 \& 12) }\end{array}$ \\
\hline MS students & 1 & 0.995 \\
HS students & 0.995 & 1 \\
\hline
\end{tabular}

Table 7 represents the preferred learning style of the students based on their previous academic score. It reveals that irrespective of previous academic score all students tend to show kinaesthetic learning style as their most preferred learning style. Furthermore, low achievers prefer kinaesthetic learning style as their most preferred way of learning $(33.33 \%)$.

\section{Table 7}

Preferred Learning Style Based on Academic Score

\begin{tabular}{ccccc}
\hline Learning style & $\begin{array}{c}\text { Academic score } \\
(35-50 \%)\end{array}$ & $\begin{array}{c}\text { Academic score } \\
(51-65 \%)\end{array}$ & $\begin{array}{c}\text { Academic score } \\
(66-75 \%)\end{array}$ & $\begin{array}{c}\text { Academic score } \\
(76 \%+)\end{array}$ \\
\hline V & $20.98 \%$ & $15.32 \%$ & $17.09 \%$ & $17.11 \%$ \\
A & $33.33 \%$ & $31.77 \%$ & $31.06 \%$ & $30.56 \%$ \\
R & $12.35 \%$ & $21.89 \%$ & $20.65 \%$ & $21.47 \%$ \\
K & $33.33 \%$ & $31.03 \%$ & $31.19 \%$ & $30.85 \%$ \\
\hline
\end{tabular}

Table 8 shows the correlation between preferred learning styles in academic scores (AS) of the students. It is evident that for those respondents, the preferred learning style scores were positively correlated though the degrees of association vary. There is high degree positive correlation of students whose academic scores are $66-75 \%$ and $76+$ indicating that high achievers' most preferred learning styles are same.

\section{Table 8}

Correlation between the Preferred Learning Styles based on Previous Academic Score

\begin{tabular}{lcccc}
\hline & AS (35-50\%) & AS (51-65\%) & AS (66-75\%) & AS (76\%+) \\
\hline AS (35-50\%) & 1 & & & \\
AS (51-65\%) & 0.76 & 1 & & \\
AS (66-75\%) & 0.85 & 0.99 & 1 & 1 \\
AS $(76 \%+)$ & 0.82 & 0.99 & 0.998 & \\
\hline
\end{tabular}

\section{Discussion}

The preferred learning styles of NCS students were aural and kinaesthetic and these findings are consistent with other studies (Das et al., 2020; McKenna et al., 2018; Reid, 1987).

The preferred learning style scores of males were positively correlated with those of females indicating that preferred learning styles of male and female students are essentially the same in this study. 
This finding was inconsistent with most learning style research (Espinoza-Poves et al., 2019; Jones et al., 2003). This inconsistent finding may be attributed to a variety of factors including contextual setting, individual differences, past educational background, and relatively small sample size. As there was a high degree positive correlation in preferred learning style based on gender, it evidently signified that, genderwise, segregation during teaching is not required.

The high correlation of preferred learning style between MS and HS students indicated that teachers teaching in both the grade levels can adopt similar teaching strategies. This finding was inconsistent with one by Espinoza-Poves et al. (2019) showing that the learning style was not associated with socio demographic variables (sex, level of education \& previous academic score). The inconsistent finding could be attributed to the contextual setting, cultural setting and socio-economic background of students.

\section{Conclusion}

The preferred learning styles of NCS students in the VARK tool in the present study were aural and kinaesthetic while the least preferred was visual. The findings of this study have important implications for learning atmosphere of NCS and for pedagogical practices of teachers as well. First, despite their diverse intuitive levels about individual differences in the ways students learn, many of them may still be unaware of their learning preferences in general. Creating and developing students' awareness of their own learning styles may be quite helpful in increasing control of their learning habits and strategies, which should in turn, influence their academic performance.

Second, as students hold and share diverse personal experiences, knowledge bases, and learning styles to the classroom, they may require multi-faceted teaching pedagogy for effective learning. Teachers should employ a variety of pedagogical approaches in their teaching. Research on teacher effectiveness has shown that successful teachers tend to be those who are able to use a range of teaching strategies and who use a range of interaction styles, rather than a single, rigid approach to teaching and learning (DarlingHammond, 2000). Third, as our understanding of our students' learning and cognition increases, in a way, that permits productive professional development among our teaching fraternity.

This study found existence of high degree positive correlation between the preferred learning styles based on gender, grade levels and academic score of the students. This indicated that the preferences of most of the students were same and kinaesthetic and aural infused pedagogy could be incorporated by teacher to enhance the academic excellence of students.

\section{Recommendations}

An effective teacher must have knowledge of students' learning styles apart from pedagogical 
knowledge, so the assessment of students' learning styles using VARK tools in the beginning of the academic year is recommended. This study recommends teachers to use mostly aural and kinaesthetic teaching strategies as students' preferences of learning were found to be these two approaches.

Moreover, this study recommends the District Education Officers, School Management body and related stakeholders to explore possibilities of providing teachers with tailor-made teaching pedagogies and professional development programmes that will cater to the needs of those aural and kinaesthetic learners.

\section{Limitations}

This study had some potential limitations that may have affected the results. It was limited to a single higher secondary school. The findings of this study can neither be inferred nor generalised as it was purely as case study of one school. In addition, the study just attempted to understand the preferred earning styles of students and it did not look into the causes, reasons, in-depth analyse of students' learning abilities. Future research projects might attempt to replicate this study with additional refinement of variables related to the learning styles of students such as motivation, study habits and learning environments. The study could be carried out to identify specific learning styles required for different subjects through inclusion of qualitative means like interviews and focus groups to generate more authentic results.

\section{References}

Butler, T. J. (2004). Students' learning styles and their preferences for online instructional methods. [Unpublished Dissertation Thesis]. Seton Hall University.

Creswell, J. W. (2003). Research design: Quantitative, qualitative and mixed method approaches ( $2^{\text {nd }}$ ed.) Sage Publication, Inc.

Dalaman, O., Can, S., \& Durukan, E. (2019). An investigation of pre-service basic education teachers learning styles in terms of different variables. Educational Research and Reviews, 14(5), 162-167.

Darling-Hammond, L. (2000). Teacher quality and student achievement: A review of state policyevidence. Educational Policy Analysis Archives, 8(1), 2-50.

Das, A., Chakraborty, D., \& Sukul, B. (2020). Learning styles of undergraduate medical studentsA cross sectional study using VARK questionnaire. Journal of Indian Academy of Forensic Medicine, 42(1), 49-53. https://doi.org/10.5958/0974-0848.2020.00014.7 
Espinoza-Poves, J. L., Miranda-Vílchez, W. A., \& Chafloque-Céspedes, R. (2019). The VARK learning styles among university students of business schools. Propósitos y Representaciones, 7(2), 401-415.

Flavin, B. (2019, May 06). Different types of learners: What college students should know. Retrieved from https://www.rasmussen.edu/student-experience/college-life/mostcommon-types-of-learners

Fleming, N. D. (1995). I'm different; not dumb. Modes of presentation (VARK) in the tertiary classroom. In A. Zelmer, (Ed.), Research and development in higher education:

Proceedings of the 1995 annual conference of the Higher Education and Research Development Society of Australasia (HERDSA) (pp. 308-313). HERDSA.

Jones, C., Reichard, C., \& Mokhtari, K. (2003). Are students learning styles discipline specific? Community College Journal of Resource and Practice. 27(5), 363-375. http://dx.doi.org/10.1080/713838162

Karim, H. (2014). Using VARK approach for assessing preferred learning styles of first-year medical sciences students: A survey from Iran. Journal of Clinical and Diagnostic Research, 8(8), https://doi.org/10.7860/JCDR/2014/8089.4667

Li, C., \& Lalani, F. (April 29, 2020). The rise of online learning during the COVID-19 pandemic, World Economic Forum. Retrieved from https://www.weforum.org/agenda/2020/04/coronavirus-education-global-covid19online-digital-learning/

McKenna, L., Copnell, B., Butler, A. E., \& Lau, R. (2018). Learning style preferences of Australian accelerated postgraduate pre-registration nursing students: A cross-sectional survey. Nurse Education in Practice, 28, 280-284. https://doi.org/10.1016/j.nepr.2017.10/.011

Ministry of Education. (2014). Bhutan education blueprint 2014-2024. Thimphu: Ministry of Education.

Nangkor Central School. (2018). Student handbook. Bhutan

Reid, J. M. (1987). The learning style preferences of ESL students. TESOL Quarterly, 21(1), 87111. https://doi.org/10.2307/3586356 
JISTE, Vol. 25, No. 1, 2021

Romanelli, F., Bird, E., \& Ryan, M. (2009). Learning styles: A review of theory, application and best practices. American Journal of Pharmaceutical Education, 73(1), 9. https://doi.org/10.5688/aj730109

The VARK Questionnaire. (2019). Retrieved from https://vark-learn.com/the-vark-questionnaire/

Willingham, D. T., Hughes, E. M., \& Dobolyi, D. G. (2015). The scientific status of learning styles theories. Teaching of Psychology, 42(3), 266-271.

\section{Authors}

Prem Prasad Timsina, (M.Sc.), Nima Tshering, (M.BA), Rinchen Sherab, M.A.(Eng), Karma Dawa M. A. (Dzo), Tshering Dorji, M. A. (Hist.), Phurba Tashi, M. A. (Pub.Adm), Ugyen Tshewang, (M.Ed.Maths), are teachers and administrators teaching different subjects in Nangkor High School, Bhutan. Our belief is working together as a professional learning community intended on improving students' achievements. Our research interest is finding evidence-based instructional designs and educational practices. 